\title{
Dienst am Kunden
}

Liebe Leserinnen, liebe Leser,

Unerfahren und mit einem Überschuss an Vertrauen fängt der Mensch das Leben an. Erst später merkt er, dass Vertrauen nicht immer gerechtfertigt ist, und er lernt mit der Zeit, wann eher Misstrauen angebracht ist. Beides, Ver- und Misstrauen, stellt sich intuitiv ein. Beides ist zukunftsbezogen, irrational und riskant; riskant ist insbesondere das Vertrauen. Aber beides erspart die Analyse der anstehenden Umstände und das Durchdenken der Alternativen. Es führt zu raschen Entschlüssen und macht so das Leben einfacher.

So viel zum Vertrauen im Individualbereich. Nicht weniger wichtig ist Vertrauen in der Gesellschaft, vor allem im Wirtschaftsleben. Dort wird es sogar vorausgesetzt. Ohne Vertrauen in den Partner kommt kein Geschäft zustande. Ein Klima des Vertrauens belebt die Wirtschaft. Schwindet es und stellt sich Misstrauen ein, bleiben die positiven Entschlüsse aus und die wirtschaftlichen Vorgänge frieren ein. Ein Klima des Vertrauens ist Billionen wert. Das zeigt die aktuelle Bankenkrise. Den Banken ist das Vertrauen in die Bonität des Partners ausgegangen; sie leihen einander kein Geld mehr. Die eigenen Interessen zu sichern, ist ihnen zur Zeit wichtiger, als eine Partnerschaft, die unersprießlich werden könnte. Man muss sehen: Das Misstrauen mag zur Bankenkrise geführt haben; in der Krise selbst kann es zwar lähmend aber auch verständlich sein.

Der Datenschutz, meine ich, beruht primär auf Misstrauen. Man möchte seine Daten vor Missbrauch durch nicht-vertrauenswürdige, anonyme Mächte gesichert wissen. Dass der Datenschutz das mit seiner rechtlichen Regulierung und Durchsetzung in der Tat leistet, ist nicht vollkommen gewiss; die Gewissheitslücke muss ebenfalls durch Vertrauen überbrückt werden; sie sollte aber weniger davon beanspruchen als der ungeschützte Fall.

Nun etwas Erlebtes: Neulich erhielt ich eine Kurzmitteilung meiner Bank. Zur Unterschrift angeheftet war eine (freiwillige) „Einwilligungserklärung zur Übermittlung, Verarbeitung und Nutzung von Daten", bezogen auf eine erweiterbare Reihe von 12 Gesellschaften aus dem Kreditgewerbe. Zu übermittelnde Daten: Meine Personalien, Kontokorrent-Daten, Karten, Einlagen, Kredite und Verwahrungsgeschäfte - also fast alles, was meine Bonität ausmacht. Meine Einwilligung sollte, sagte die Bank, dem Interesse einer umfassenden Beratung und Betreuung ihrer Kunden - also z.B. meiner Person - dienen, sollte also mein Vertrauen in sie festigen. Ich stutzte. Seltsam, sagte ich mir, die Bank will die angegebenen Gesellschaften über meine Bonität informieren und das soll ihr helfen, mich besser zu beraten und zu betreuen? Bei aller Sympathie für meine Bank: Das ist, meine ich, ein leicht hingeworfener Werbespruch, aber nicht die Wahrheit.

Was aber ist die Wahrheit? Ich kann da nur raten. Ich habe das notwendige Vertrauen in meine Bank. Bevor ich es durch Misstrauen ersetze, frage ich mich, warum mir die Bank statt eines leeren Spruchs nicht die Wahrheit sagt. Dabei fällt mir die Bankenkrise und das gegenseitige Misstrauen der Banken ein. Könnte es sein, dass die Bank von den in der Erklärung bezeichneten Kreditinstituten Geld leihen möchte? Sie möchte also diese von ihrer Bonität überzeugen, und das per Weitergabe der Bonität ihrer Kunden. Kann das so sein, oder will sie lediglich einen nützlichen Vorrat an jederzeit verfügbaren Weitergaberechten anlegen? Will sie ihren Partnern meine Daten überlassen, damit diese mir ungefragt ",helfen “ können? Ich bin mir, liebe Leserinnen und Leser, nicht sicher, dass eines davon das Verhalten der Bank erklärt. Jedes davon könnte albern sein. Ich meine aber, dass die Vorgabe der Bank - Dienst am Kunden - zwar Vertrauen heischend und daher zweckdienlich sein mag, aber noch viel alberner als meine Erklärungen ist. Vor solcher zweckdienlicher Albernheit und Aushöhlung des Datenschutzes schützt uns offenbar nichts, auch nicht der Datenschutz, so misstrauisch er sein mag.

Mit freundlichen Grüßen, Ihr

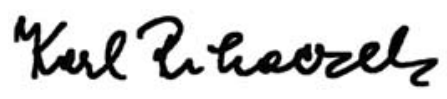

